\title{
Band Gap Determination of Copper Doped Tungsten Diselenide Single Crystals by Optical Absorption Method
}

\author{
M. P. Deshpande, M. N. Parmar, Nilesh N. Pandya, Sandip V. Bhatt, Sunil Chaki* \\ Department of Physics, Sardar Patel University, Vallabh Vidyangar, Gujarat, 388120, India
}

\begin{abstract}
Absorption spectrum of copper $(\mathrm{Cu})$ doped $\mathrm{WSe}_{2}(\%$ of $\mathrm{Cu}=0.0,0.5,1.0)$ single crystals were obtained in the range $700 \mathrm{~nm}$ to $1450 \mathrm{~nm}$. The energy gap and phonon energies were determined for the crystals from the spectrum using two and three dimensional models. This study reflects that indirect transition is dominant in these crystals. On the basis of three dimensional models it was not possible for us to decide whether the indirect inter-band transition is forbidden or allowed type. Hence, different plots were made for two dimensional models, which showed that indirect forbidden transition holds accurately for this sample whereas indirect allowed type transition is not valid. The phonon energies calculated for these samples corresponds to the energies associated with optical phonons. The obtained results are discussed in details in this paper.
\end{abstract}

Keywords Copper doped tungsten diselenide, Single crystals, Absorption coefficient, Bandgap

\section{Introduction}

The layered transition metal dichalcogenides (TMDC's) having general equation $\mathrm{MX}_{2}$ (M-transition metals like Mo, $\mathrm{W}, \mathrm{Zr}, \mathrm{Nb}, \mathrm{Ta}$, etc. and $\mathrm{X}-$ chalcogens like $\mathrm{S}, \mathrm{Se} \& \mathrm{Te}$ ) in single crystals and thin films form have been used in fabricating high efficiency solar cells, rechargeable batteries and high temperature solid lubricants[1-4]. The TMDC semiconductors are of interest in solar energy conversion due to the regular arrangement of structural lattice with cations and anions[1]. Of the TMDCs, $\mathrm{WSe}_{2}$ is a semiconductor with a bandgap in the range of $1.2-2 \mathrm{eV}$, depending on how the nonstoichiometry differs from the ideal W:Se ratio of 1:2[5]. The $\mathrm{WSe}_{2}$ is a black or gray color odorless material, possessing good thermal stability and a high melting point[6]. The high optical absorption, layered type of arrangement between cations, high resistance against photocorrosion and matching bandgap makes $\mathrm{WSe}_{2}$ a potential candidate for photoelectrochemical conversion and photovoltaic solar energy conversion. $\mathrm{WSe}_{2}$ has been used in a number of technologies such as high temperature solid lubrication and rechargeable batteries[7-8]. The $\mathrm{WSe}_{2}$ structure is characterized by a stacking of two-dimensional sandwich units (Se-W-Se) along the c-axis separated from each other by the so-called Van der Waals gap, the Se atoms forming the outer hexagonal dense planes[1]. The band gap of these materials plays an important role for its application hence it becomes necessary to determine it accurately.

* Corresponding author:

sunilchaki@yahoo.co.in (Sunil Chaki)

Published online at http://journal.sapub.org/ materials

Copyright (C) 2011 Scientific \& Academic Publishing. All Rights Reserved
Herein, the authors report detailed study on determination of band gap of $\mathrm{WSe}_{2}$ single crystals having copper doped with three different percentage viz $\%$ of $\mathrm{Cu}=0.0,0.5,1.0$. The optical absorption technique was employed to determine the phonon energies and indirect transition in the crystals.

\section{Experimental Methods}

The absorption spectra for the different concentration of $\mathrm{Cu}$ doped $\mathrm{WSe}_{2}(\%$ of $\mathrm{Cu}=0.0,0.5,1.0)$ single crystals were obtained using UV-VIS-NIR Shimadzu Spectrophotometer in the range $700 \mathrm{~nm}$ to $1450 \mathrm{~nm}$ as shown in Figure 1(a, b, c) respectively. Single crystals grown in thin flakes of approximately $0.35 \mu \mathrm{m}$ thickness were pasted on a thick black paper with a cut exposing the crystal flake to the incident light. The reference used is a replica of the black paper, having the cut in exactly the same position as the crystal flake.

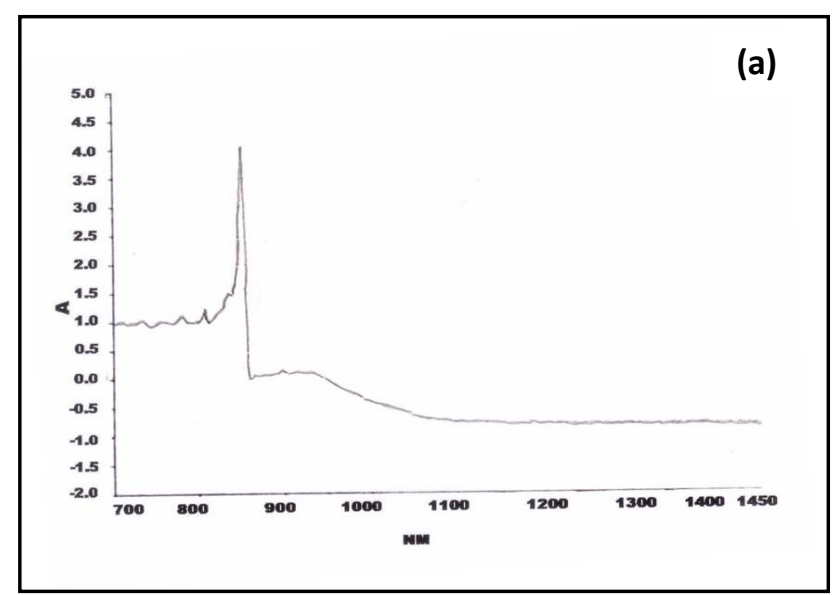



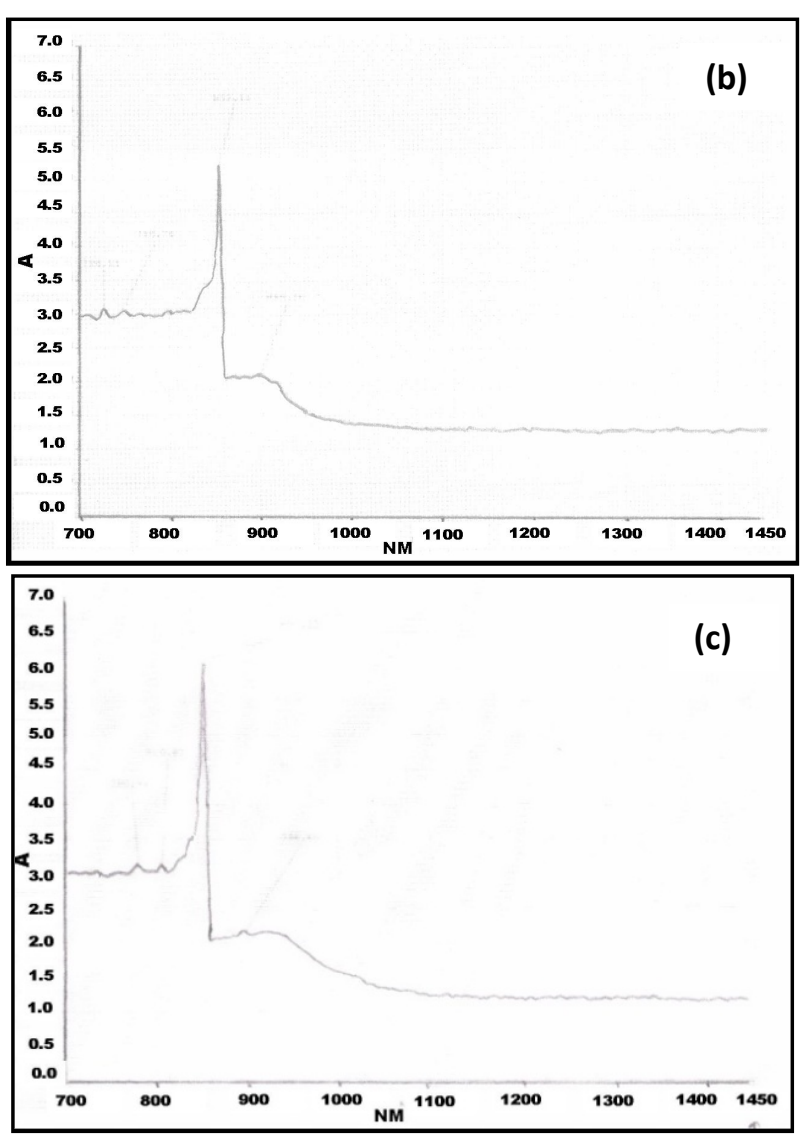

Figure 1. Absorption spectra for copper doped $\mathrm{WSe}_{2}$ single crystals, $\%$ of $\mathrm{Cu}$ (a) 0.0 (b) 0.5 (c) 1.0 respectively

\section{Results and Discussion}

In order to analyze the results from these spectra in the vicinity of the absorption edge, values of absorption coefficient ' $\alpha$ ' were determined at every step of $2.5 \mathrm{~nm}$ individually for all samples. Then these absorption spectra were analyzed on basis of already reported[9 - 11] three and two dimensional models. Figure 2 ( a, b, c ) and Figure 3 ( a, b, c ) shows the variation of the quantities $(\alpha h v)^{1 / 3}$ and $(\alpha h v)^{1 / 2}$ versus $\mathrm{h} v$ for different $\%$ of $\mathrm{Cu}$ doped $\mathrm{WSe}_{2}(\%$ of $\mathrm{Cu}=0$, $0.5,1.0)$ single crystals respectively.

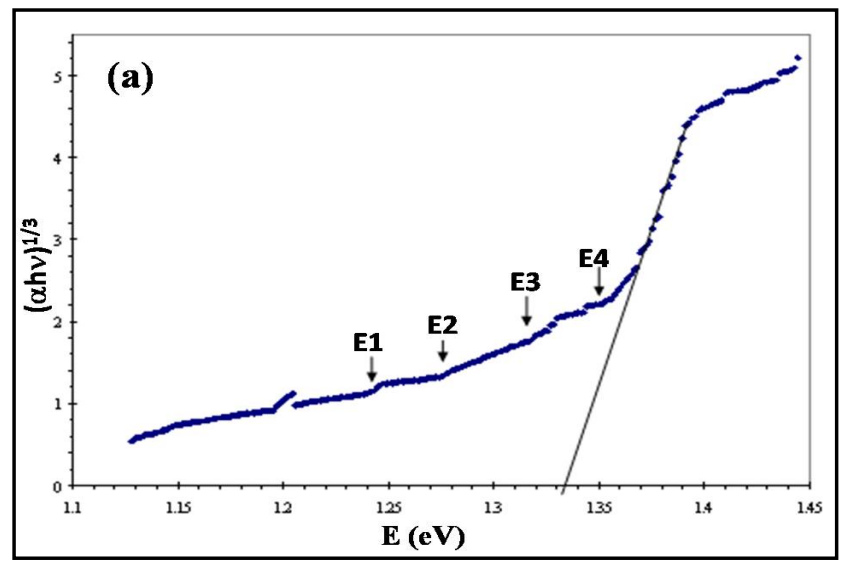

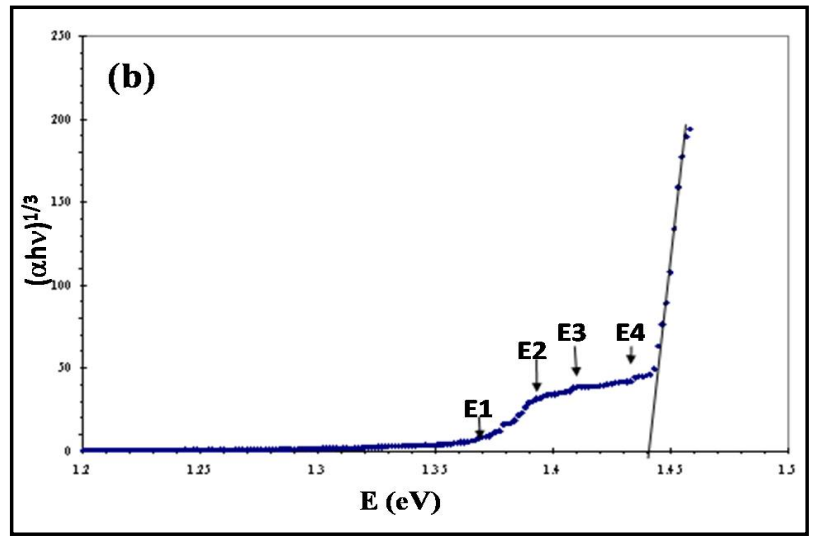

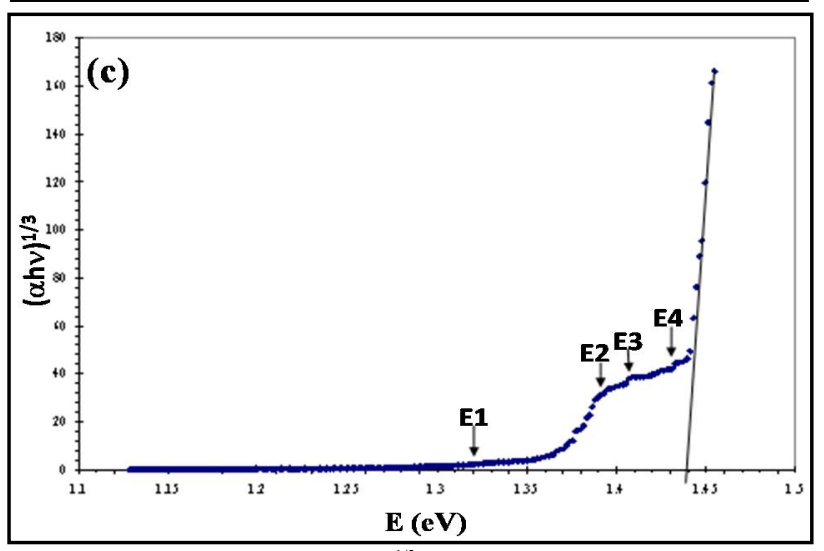

Figure 2. (a, b, c) Plot of $(\alpha h v)^{1 / 3}$ versus $\mathrm{E}(\mathrm{eV})$ for different $\%$ of copper $(\mathrm{Cu})$ doped $\mathrm{WSe}_{2}$ single crystals, $\%$ of $\mathrm{Cu}$ (a) 0.0 (b) 0.5 and (c) 1.0 respectively
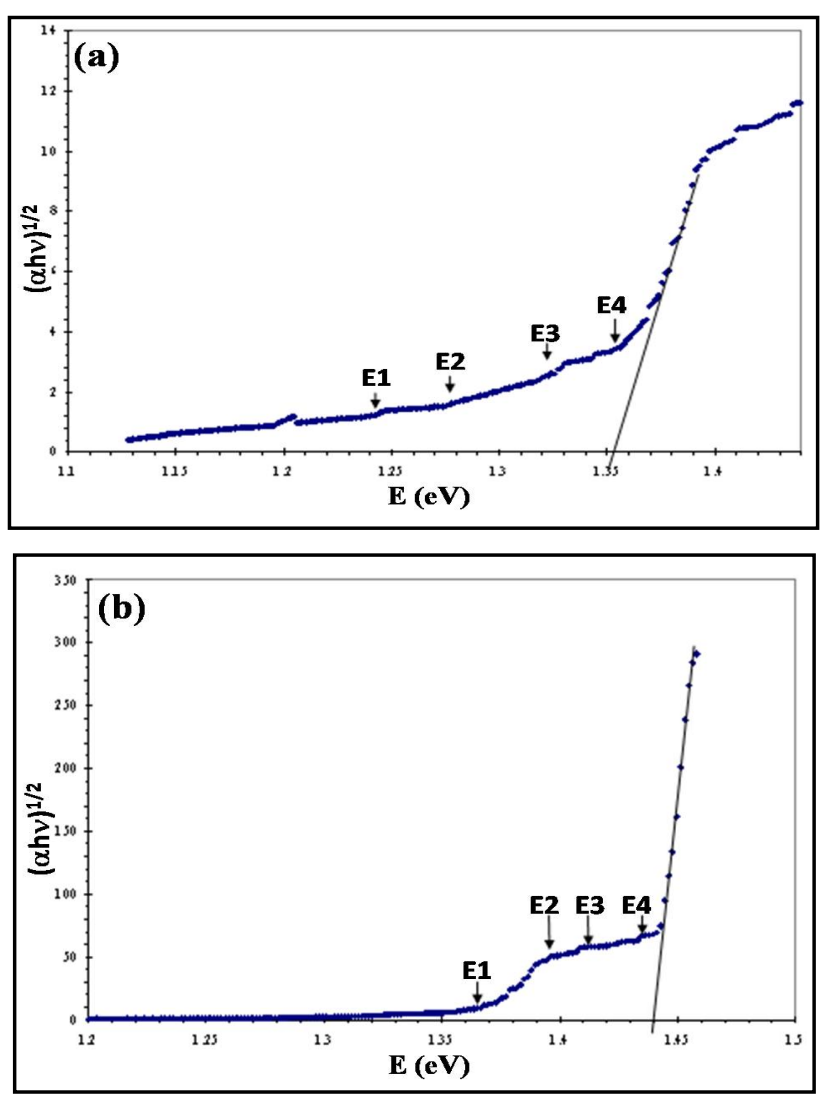


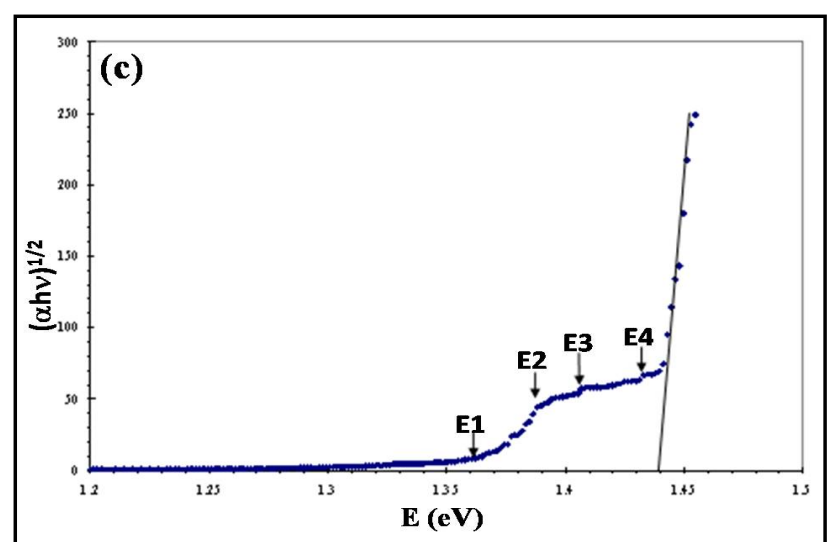

Figure 3. (a, b, c) Plot of $(\alpha h v)^{1 / 2}$ versus $\mathrm{E}(\mathrm{eV})$ for different $\%$ of copper $(\mathrm{Cu})$ doped $\mathrm{WSe}_{2}$ single crystals, $\%$ of $\mathrm{Cu}$ (a) 0.0 (b) 0.5 and (c) 1.0 respectively

All these plots of Figure 2 and Figure 3 shows broken straight lines which indicates that the inter-band transition is associated with absorption and emission of two phonons. The knees indicated by $E_{1}, E_{2}, E_{3}$ and $E_{4}$ indicate the beginning of the following processes respectively: absorption of $1^{\text {st }}$ phonon, absorption of $2^{\text {nd }}$ phonon, emission of $2^{\text {nd }}$ phonon and emission of the $1^{\text {st }}$ phonon. From above results, it is clear that $\mathrm{Cu}$ doped $\mathrm{WSe}_{2}(\%$ of $\mathrm{Cu}=0.0,0.5,1.0)$ single crystals exhibits an indirect inter-band transition near the fundamental absorption edge with two independent phonons. On the basis of three dimensional model, it is not possible to decide if the indirect inter-band transition is of the forbidden or allowed type. As observed from Figure $2(a, b, c)$ and Figure $3(a, b, c)$ both types seem to be probable.

This discrepancy can be resolved if measurements are carried out at low temperature[12]. It is being already shown by[13] that even if the measurements are not done at low temperature then analysis of the absorption spectra at room temperature on the basis of two dimensional model can provide this information. Figure $4(a, b, c)$ and Figure 5 (a, $\mathrm{b}, \mathrm{c})$ shows the spectral variation of $\alpha^{1 / 2}$ vs $h v$ and $\alpha$ vs $h v$ for $\mathrm{Cu}$ doped $\mathrm{WSe}_{2}(\%$ of $\mathrm{Cu}=0.0,0.5,1.0)$ single crystals i.e. indirect forbidden and indirect allowed respectively.

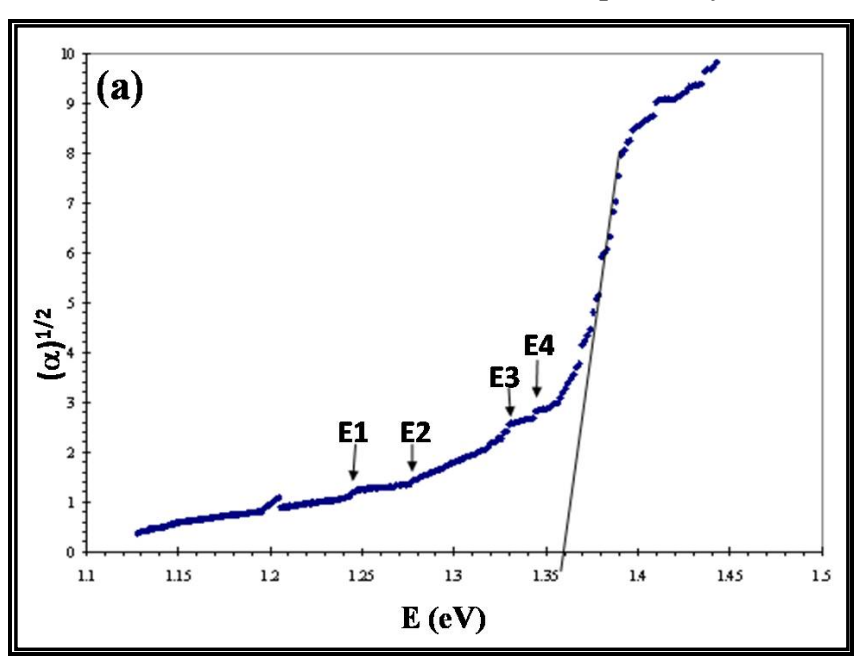

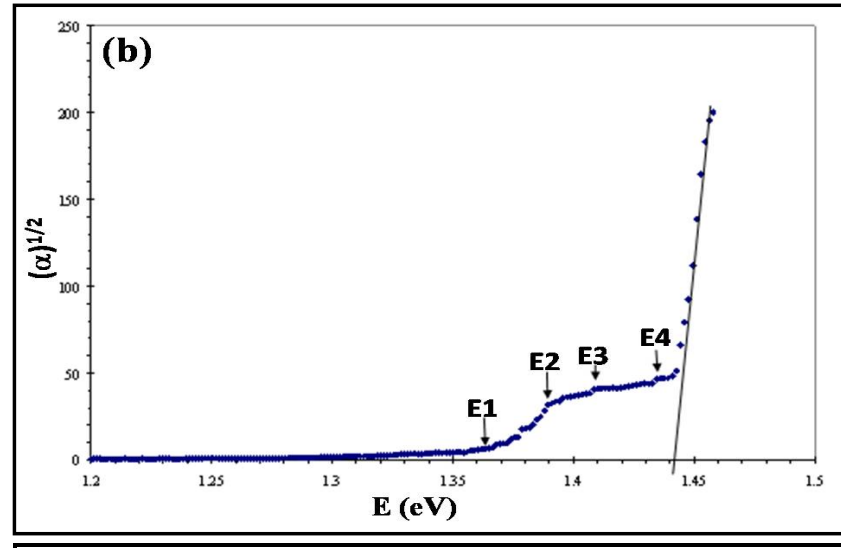

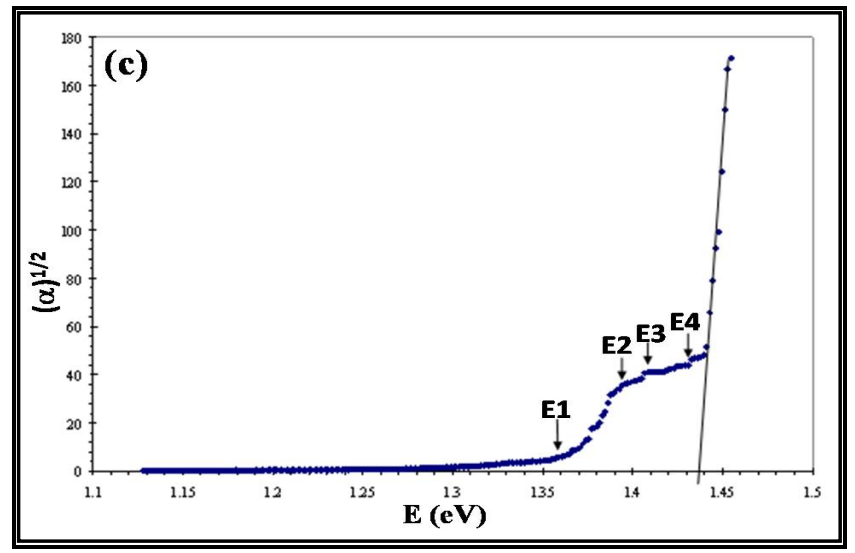

Figure 4. (a, b, c) Plot of $(\alpha)^{1 / 2}$ versus $\mathrm{E}(\mathrm{eV})$ for different $\%$ of copper $(\mathrm{Cu})$ doped $\mathrm{WSe}_{2}$ single crystals, \% of $\mathrm{Cu}$ (a) 0.0 (b) 0.5 and (c) 1.0 respectively
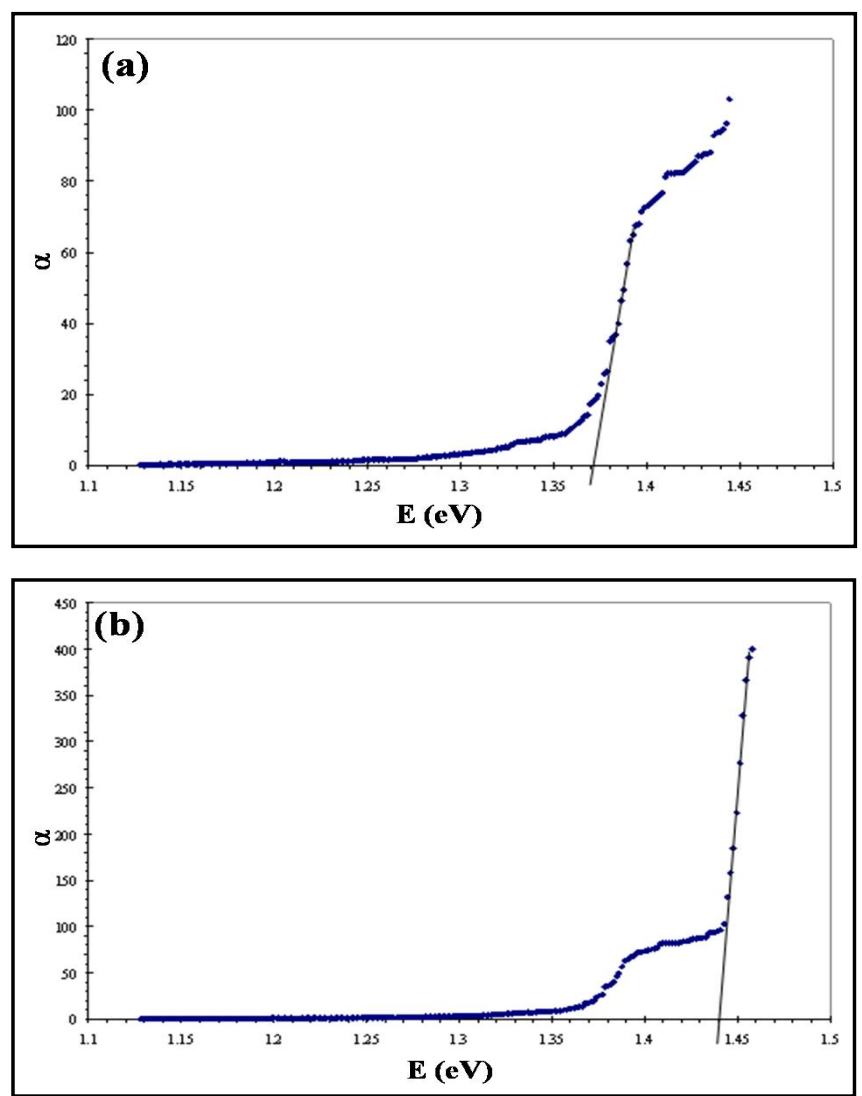


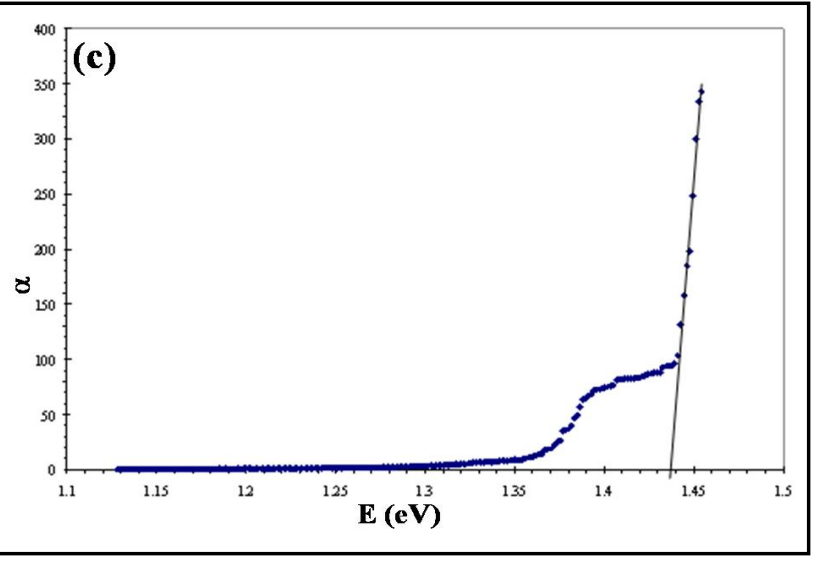

Figure 5. (a, b, c) Plot of $\alpha$ versus $\mathrm{E}(\mathrm{eV})$ for different $\%$ of copper $(\mathrm{Cu})$ doped $\mathrm{WSe}_{2}$ single crystals, \% of $\mathrm{Cu}$ (a) 0.0 (b) 0.5 and (c) 1.0 respectively

Since discontinuity in steps is not being observed as seen in Figure $5(\mathrm{a}, \mathrm{b}, \mathrm{c})$ therefore the two dimensional indirect allowed transition is excluded. In order to make an accurate determination of the points of discontinuities in Figure 2 ( $a, b$, c), Figure $3(a, b, c)$ and Figure $4(a, b, c)$, author has followed the method adopted by[10-11].

The values of $E_{1}, E_{2}, E_{3}$, and $E_{4}$ indicate the points of discontinuities in the plots of Figure $2(a, b, c)$, Figure $3(a, b$, c) and Figure $4(a, b, c)$ respectively. The indirect energy gaps obtained from these values of $\mathrm{E}_{1}, \mathrm{E}_{2}, \mathrm{E}_{3}$ and $\mathrm{E}_{4}$ are given by

$$
E_{g}=\frac{E_{1}+E_{4}}{2}=\frac{E_{2}+E_{3}}{2}
$$

and the phonon energies are given by

$$
E_{p 1}=\frac{E_{4}-E_{1}}{2} \text { and } E_{p 2}=\frac{E_{3}-E_{2}}{2}
$$

These calculated values are given in Table 1, Table 2 and
Table 3 for all the samples.

The values of $\mathrm{E}_{\mathrm{g}}$ ' can also be obtained from the intersection of the linear portion of the graphs in Figure $2(a, b, c)$, Figure $3(a, b, c)$ and Figure $4(a, b, c)$ with the energy axis for zero absorption which are given in Table 1 and Table 2 which has close resemblance with the value obtained by expression (1).

For the determination of the direct band gap $\left(\mathrm{E}_{\mathrm{g}}\right)$ using three dimensional model, we plotted variation of $(\alpha h v)^{2}$ vs $h v$ and $(\alpha h v)^{2 / 3} v s \mathrm{~h} v$ for $\mathrm{Cu}$ doped $\mathrm{WSe}_{2}(\%$ of $\mathrm{Cu}=0.0$, $0.5,1.0)$ single crystals for allowed and forbidden transitions. This did not give a good account of absorption edge in our case and hence are excluded and hence figures are not shown.

Thus according to the two dimensional model the indirect transition is confirmed to be forbidden type for $\mathrm{Cu}$ doped $\mathrm{WSe}_{2}(\%$ of $\mathrm{Cu}=0.0,0.5,1.0)$ single crystals. The value of indirect band gap lies between $1.33 \mathrm{eV}$ to $1.44 \mathrm{eV}$ (Table 2) for the $\mathrm{Cu}$ doped $\mathrm{WSe}_{2}(\%$ of $\mathrm{Cu}=0.0,0.5,1.0)$ single crystals by extrapolation. Similarly the values of indirect band gaps lies between $1.29 \mathrm{eV}$ to $1.39 \mathrm{eV}$ by energy step functions as shown in Table 1 and Table 2 respectively and are having very close resemblance with those determined by extrapolation. These results are matching with those reported by various workers[14-19]. This variation in indirect band gap might be occurring because of copper doping in host $\mathrm{WSe}_{2}$ material.

The values of phonon energies calculated are shown in Table 3 and indicates variation from $8.5 \mathrm{meV}$ to $23.5 \mathrm{meV}$ for $\mathrm{Cu}$ doped $\mathrm{WSe}_{2}(\%$ of $\mathrm{Cu}=0,0.5,1.0)$ samples and matches closely with the value of optical mode phonon energies at the centre of Briollouin zone as obtained by[20-21].

\begin{tabular}{|c|c|c|c|c|c|c|c|}
\hline$\%$ of Copper in $\mathrm{WSe}_{2}$ & Type of transition & $E_{g}^{\prime}(e V)$ & $E^{*}(e V)$ & $E_{1}$ & $E_{2}$ & $E_{3}$ & $\mathrm{E}_{4}$ \\
\hline 0.0 & \multirow{3}{*}{$\begin{array}{c}\text { Allowed } \\
\text { ( Step Function ) }\end{array}$} & 1.37 & - & - & - & - & - \\
\hline 0.5 & & 1.44 & - & - & - & - & - \\
\hline 1.0 & & 1.44 & - & - & - & - & - \\
\hline 0.0 & \multirow{3}{*}{ Forbidden } & 1.36 & 1.29 & 1.24 & 1.28 & 1.33 & 1.34 \\
\hline 0.5 & & 1.44 & 1.39 & 1.36 & 1.39 & 1.41 & 1.43 \\
\hline 1.0 & & 1.44 & 1.39 & 1.36 & 1.39 & 1.41 & 1.43 \\
\hline
\end{tabular}

Table 1. Values of indirect band gap obtained using two dimensional model for $\mathrm{Cu}$ doped $\mathrm{WSe}_{2}(\%$ of $\mathrm{Cu}=0.0,0.5,1.0)$ single crystals

\begin{tabular}{|c|c|c|c|c|c|c|c|}
\hline$\%$ of Copper in $\mathrm{WSe}_{2}$ & Type of transition & $E^{\prime}{ }_{g}(e V)$ & $\mathrm{E}_{\mathrm{g}}^{*}(\mathrm{eV})$ & $\mathrm{E}_{1}$ & $\mathrm{E}_{2}$ & $E_{3}$ & $\mathrm{E}_{4}$ \\
\hline 0.0 & \multirow{3}{*}{$\begin{array}{c}\text { Allowed } \\
\text { (Step Function ) }\end{array}$} & 1.35 & 1.30 & 1.24 & 1.28 & 1.32 & 1.35 \\
\hline 0.5 & & 1.44 & 1.40 & 1.36 & 1.39 & 1.41 & 1.43 \\
\hline 1.0 & & 1.44 & 1.40 & 1.36 & 1.38 & 1.41 & 1.43 \\
\hline 0.0 & \multirow{3}{*}{ Forbidden } & 1.33 & 1.29 & 1.24 & 1.27 & 1.32 & 1.35 \\
\hline 0.5 & & 1.44 & 1.39 & 1.37 & 1.39 & 1.41 & 1.43 \\
\hline 1.0 & & 1.44 & 1.38 & 1.32 & 1.39 & 1.41 & 1.43 \\
\hline
\end{tabular}

Table 2. Values of indirect band gap obtained using three dimensional model for $\mathrm{Cu}$ doped $\mathrm{WSe}_{2}(\%$ of $\mathrm{Cu}=0.0,0.5,1.0)$ single crystals

$\mathrm{E}_{\mathrm{g}}^{\prime} \rightarrow$ Values of indirect band gap obtained from extrapolation.

$\mathrm{E}_{\mathrm{g}}^{*} \rightarrow$ Values of indirect band gap obtained from energy step functions.

Table 3. Values of phonon energy of $\mathrm{Cu}$ doped $\mathrm{WSe}_{2}(\%$ of $\mathrm{Cu}=0,0.5,1.0)$ single crystals

\begin{tabular}{|c|c|c|}
\hline \% of Copper in $\mathrm{WSe}_{2}$ & $\mathrm{E}_{\mathrm{p} 1}(\mathrm{meV})$ & $\mathrm{E}_{\mathrm{p} 2}(\mathrm{meV})$ \\
\hline 0.0 & 53.5 & 23.5 \\
\hline 0.5 & 33.5 & 8.5 \\
\hline 1.0 & 36.0 & 8.5 \\
\hline
\end{tabular}




\section{Conclusions}

Determination of band gap by optical absorption method for $\mathrm{Cu}$ doped $\mathrm{WSe}_{2}(\%$ of $\mathrm{Cu}=0.0,0.5$ and 1.0$)$ single crystals reflects that from three dimensional model it is difficult to predict whether the indirect transition is forbidden or allowed type whereas two dimensional model confirms the indirect transition to be forbidden type.

\section{ACKNOWLEDGEMENTS}

All the authors are thankful to UGC, New Delhi for sanctioning DRS/SAP programme to the Department of Physics, Sardar Patel University which helped substantially to carry out this work.

\section{REFERENCES}

[1] A. Aruchamy (Ed.), Photoelectrochemistry and Photovoltaics of Layered Semiconductors, Kulwer Academic Publishers, Dordrecht, 1992

[2] A. Ennaoui, K. Diesner, S. Fiechter, J. H. Mooser, F. Levy, Thin Solid Films, 1997, 311, 146

[3] S. Mary Delphine, M. Jayachandran, C. Sanjeeviraja, Mater. Chem. Phys., 2003, 81, 78

[4] M. Maret, B. Gilles, J. P. Simon, M. Verdier, I. Guhr, B. Riedlinger, M. Albrecht and G. Schatz, J. Cryst. Growth, 2005, 275, e2289

[5] Swati V. Pol, Vilas G. Pol, Jose M. Calderon-Moreno and Ahron Gedanden, J. Phys. Chem., 2008, C 112, 5356
[6] H. Haraldsen, Angew Chem. Inst. Ed., 1966, 5, 51

[7] A. H. Reshak and S. Auluck, Phys. Rev. B, 2003, 68, 195107

[8] T. Tsirlina, S. Cohen, H. Cohen, L. Sapir, M. Peisach, R. Tenne, A. Matthaus, S. Tiefenbacher, W. Jaegermann, E. A. Ponomarev, C. Levy-Clement, Sol. Energy Mater. Sol. Cells, 1996, 44, 457

[9] K Takahashi, T Arai and K Kudo, Sci. Light, 1972, 21,131

[10] V M Koshkin, V R Karas and LP Galchinetskii, Sov. Phys. Semicond., 1970, 3, 1186

[11] A M Elkorashy, J. Phys. Chem. Solids., 1986, 47,497

[12] A M Elkorashy, Proc. $14^{\text {th }}$ Int. Conf. Phys. of Semiconductors, Edinburgh, 1978, 817

[13] A M Elkorashym, $7^{\text {th }}$ Conference on Solid State Science , 15-18 April 1984, Military Technical College, Cairo, Egypt

[14] C J Lewerenz, S D Ferris, C J Doharty and H J Leamy, J. Electrochem. Soc., 1982, 129, 418

[15] H Tributsch, Solar Energy Mater., 1979, 1, 257

[16] Jager-Waldau and E. Bucher, Thin Solid Films., 1991, 200, 157

[17] CR Cabrera and H D Abruna, J. Electrochem Soc., 1988, 135 (6), 1436

[18] S H El Mahalawy and B L Evans, Phys. Stat Sol (b), 1977, 79,713

[19] R Tenne and A Wold, Appl. Phys. Lett., 1985, 47(7), 707

[20] G Lucovsky, R M White, J A Benda and J F Revelli, Phys. Rev. B, 1973, 7, 3859

[21] J I Pankove, Optical Processes in Semiconductors, PrenticeHall, Inc, Englewood Cliffs, New Jersey 